\title{
Commentary \\ Partial pressure of end-tidal carbon dioxide predicts successful cardiopulmonary resuscitation in the field
}

\author{
Max Harry Weil ${ }^{1,2}$
}

${ }^{1}$ Weil Institute of Critical Care Medicine, 35100 Bob Hope Drive, Rancho Mirage, CA 92270, USA

${ }^{2}$ Keck School of Medicine of the University of Southern California, 1975 Zonal Avenue, KAM 317, Los Angeles, CA 90087 USA

Corresponding author: Max Harry Weil, weilm@weiliccm.org

Published: 7 November 2008

Critical Care 2008, 12:190 (doi:10.1186/cc7090)

This article is online at http://ccforum.com/content/12/6/190

(c) 2008 BioMed Central Ltd

See related research by Kolar et al., http://ccforum.com/content/12/5/R115

\begin{abstract}
Kolar and colleagues contribute an additional and important incentive for rescuers to utilize end-tidal carbon dioxide tensions as a routine monitor to guide management and decision-making during cardiopulmonary resuscitation. They conclude that below-threshold levels of $14 \mathrm{mmHg}(1.5 \mathrm{kPa})$ measured after 20 minutes of cardiopulmonary resuscitation reliably predict that spontaneous circulation cannot be restored.
\end{abstract}

In their report on 737 patients who sustained out-of-hospital cardiac arrest, collected over an interval of 9 years in a wellorganized emergency medical system, Kolar and colleagues confirmed that the measurement of end-tidal carbon dioxide tension $\left(\mathrm{PetCO}_{2}\right)$ is predictive of the outcomes of cardiopulmonary resuscitation [1]. The authors provide impressive data supporting the conclusion that, in their population, failure to increase $\mathrm{PetCO}_{2}$ to levels exceeding $14 \mathrm{mmHg}(1.5 \mathrm{kPa})$ after 20 minutes of attempted resuscitation served as a reliable guide for terminating unsuccessful cardiopulmonary resuscitation. The population studied, however, differed in some respects from the majority of earlier demographic reports that the authors cited with hospital survival $<3 \%$. More than $53 \%$ survived. The majority of instances of cardiac arrest reported by them was witnessed, and as many as onethird of victims received bystander cardiopulmonary resuscitation - favoring improved outcomes. Fatal outcomes, as anticipated, were associated with a doubling of the response time of professional rescuers, presumably in the absence of bystander utilization of automated external defibrillators, especially since a majority of survivors had shockable ventricular fibrillation or ventricular tachycardia.

As the authors pinpoint, $\mathrm{PetCO}_{2}$ has evolved into a technically facile and singularly useful monitor to guide cardiopulmonary resuscitation. $\mathrm{PetCO}_{2}$ provides an indirect measurement of the cardiac output generated by chest compression and thereby guides the effectiveness of the procedure, including chest compression, to achieve better outcomes. It also allows uninterrupted chest compression because it promptly signals the return of spontaneous circulation [2]. PetCO $\mathrm{CO}_{2}$ is likely to promptly identify asphyxia, in contrast to primary cardiac causes of arrest as previously reported by one of the present authors [3]. $\mathrm{PetCO}_{2}$ measurement during cardiopulmonary resuscitation may not require routine endotracheal intubation, which usually interrupts chest compression and under crisis conditions has a high failure rate and disproportionate airway injury. The alternatives of a laryngeal mask airway or even a facial mask incorporating a mainstream carbon dioxide sensor may be utilized. Because injection of bolus epinephrine produces a sharp although transient reduction in $\mathrm{PetCO}_{2}$ when injected intravenously [4], clinicians would best be alerted to this potential error.

These considerations notwithstanding, Kolar and colleagues contribute an additional and important incentive for rescuers to utilize $\mathrm{PetCO}_{2}$ as a routine monitor to guide management and decision-making during cardiopulmonary resuscitation.

\section{Competing interests}

The author declares that they have no completing interests.

\section{References}

1. Kolar M, Krizmaric M, Klemen P, Grmec S: Partial pressure of end-tidal carbon dioxide successful predicts cardiopulmonary resuscitation in the field: a prospective observational study. Crit Care 2008, 12:R115.

2. Falk J, Rackow EC, Weil MH: End-tidal carbon-dioxide concentration during cardiopulmonary resuscitation. $N$ Engl J Med 1988, 318:607-611.

3. Grmec S, Lah K, Tusek-Bunc K: Difference in end-tidal $\mathbf{C O}_{2}$ between asphyxia cardiac arrest and ventricular fibrillation/ pulseless ventricular tachycardia cardiac arrest in the prehospital setting. Crit Care 2003, 7:R38-R44.

$\mathrm{PetCO}_{2}=$ end-tidal carbon dioxide tension. 
4. Cantineau JP, Merckx P, Lambert Y, Sorkine M, Bertrand C, Duvaldestin P: Effect of epinephrine on end-tidal carbon dioxide during prehospital cardiopulmonary resuscitation. Am J Emerg Med 1994, 12:267-270. 